\title{
MENTAL HEALTH AMONG JOINT AND SEPARATE FAMILY'S WOMEN: A COMPARATIVE STUDY
}

\author{
Ahir Archana P*
}

\begin{abstract}
The main purpose of this research was to find out the mean difference between joint family and separate family's women in mental health. The total sample consisted 60 women were taken. The research tool for mental health was measured by Dr. Jagdish and Dr. A. K. Srivastava. Here ' $t$ ' test was applied to check the significance of mental health in joint and separate family's women.

Result shows that significant difference between joint and separate family's women in mental health.

\section{Introduction :}

'Mental health is the strength and hidden ability which keeps the human stable in the critical circumstances.' but in the present era, mental health of the person has been the burning problem because the ambition of the person has been raised. The people want to achieve the physical prosperity. The present era is the era of science and technology. The people have become aware of physical health. But in the attainment of physical prosperity, the people have been losing their mental health. If we want to create the total healthy atmosphere, we should think of mental health of the people of the society, because according to Bacon, "mind is the caption of the ship of body. so maintenance and care of mental health is very important.'
\end{abstract}

\section{Definitions:}

"Let us define mental health as the adjustment of human-beings to the world and to one another with a maximum of effectiveness and happiness."

- Karl menninger

\footnotetext{
* Department of psychology, Maharaja Krishnkumarshinji, Bhavnagar University

(C) www.ijip.in
} 
"Mental health means a proper study of the aspects which affects an individual or society coordination and also optimum use of the aspects of that study."

- Klein

"In individual view or societal view or in any kind of behavioral growth which requires a great strength to solve the problem is mental health."

- Hadley

"Mental health includes precautionary steps to prevent mental illness and through it growth can be seen in mental health."

- Walter J. Coville

As the development in human life has been increase, offensive nature could be seen increased. Thus, in the era of competitive and changing world, mental health and stability has become one of the most important questions. Many problems regarding economical, social, political, professional, violent incidents intoxicate medicines, rap, an employment, strike drawer have become to be discussed whose answers are still an decided, because from people like intelligent, thoughtful and literate to people like in intelligent, non-thoughtful and illiterate have faith in Jogi, Jati, Bhuva, protecton string, beliefs, bias and fanatics. So, with the reference to mental health, we are living still in dark age. Therefore, the people should be imported education. Mental health distorts when a person disobey the demand of super conscious mind. Because according to corchin, "positive mental health is the key of person's cohesive development." The person who holds mental health keeps confidence on the self and accepts the self in factual conditions. The life of person has goal for the future.

According to our Indian tradition, joint family's concept is very important. One of the opinions is that and individual who lives in joint family, makes his works with co-operations with others in his family. And also they share their problems and happiness to one another. They share their responsibilities as well and this is how they live their life happily in this kind of atmosphere. Hence, in our country the concept of mental health is at its peak compared to the western countries.

But, in present time in India, the concept of joint family and nuclear (separate) family is increasing. One of the opinions says that in separate family the responsibilities also increase compared to joint family. At the same time he can make noticeable progress in life and he can have his individual decisions which are really important in one's life. Thus, all the 
problems, responsibilities, advantages, limitations of women are different in both kinds of families. Therefore, there is a noteworthy difference in mental health of women in both families.

Subhash Basu (2004) studies that the mental health problems of women, especially in the Indian context. As per World Health Organization (WHO) estimates, depression is expected to be the second largest contributor to disease burden by 2020 , and with one in every three women worldwide being afflicted by common mental disorders including depression, the mental health of women is a serious issue indeed. While studying the psychological construct of mental health, we come to understand that it is deeply embedded within an individual's social and socioeconomic relationships. Since women worldwide and more so in India, face gender based discrimination at every stage of their lives, their psychological well-being becomes a cause for great concern. This note attempts to explore the various risk and protective factors affecting the mental health of women. This note attempts to explore the various risk and protective factors affecting the mental health of women. Considering the gravity of the matter, urgent remedial measures such as understanding the underlying causes of psychological distress among women, adopting a gender-sensitive approach, working towards women's empowerment and formulating women-friendly health policies could work wonders for the mental health of Indian women.

Manisha Singh and Girish singh. 2006 The overall assessment in reveals that thought the subjective are normal in general, bat a substantial proportion is at risk of developing psychosocial stress generated problems that may affect their mental health. Modification in coping strategies and planned interventions are desirable.

\section{Objective:}

To study the mental health of joint family and separate family's women.

\section{Hypothesis:}

There is no significant difference between joint and separate family's women in mental health. 


\section{Methodology:}

- Variable :

Independent variable :
A). Joint Family's women
B). Separate Family's women

\section{Depended Variable :}

To get score of mental health among joint \& separate family's women.

- Sample :

The sample consisted of 60 (30 joint family and 30 separate family's women). Women the sample was selected by random method from Bhavnagar City.

\section{- Tools :}

In this research mental health questionnaires were used from the data collection constructed and standardized by Dr. Jagdish and Dr. A. K. Srivastava. The reliability is 0.73 and the validity is 0.54 .

\section{- Statistical Methodology:}

't' test was conducted as a statistical technique to find out the aim.

\section{Result and Discussion:}

't' Ratio of mental health of joint and separate family's women.

\begin{tabular}{|l|c|c|c|c|c|}
\hline \multicolumn{1}{|c|}{ Variable } & (N) & Mean & SD & 't' Value & $\begin{array}{c}\text { Level of } \\
\text { Significant }\end{array}$ \\
\cline { 1 - 3 } $\begin{array}{l}\text { Joint family's } \\
\text { women }\end{array}$ & 30 & 166.3 & 21.74 & \multirow{2}{*}{$4.89^{*}$} & 0.01 \\
\cline { 1 - 1 } $\begin{array}{l}\text { Separate } \\
\text { family's } \\
\text { Women }\end{array}$ & 30 & 192.03 & 18.90 & & $* \mathbf{p}<\mathbf{0 . 0 1}$ \\
\hline
\end{tabular}

The result of the present study indicates that there is clear difference between the joint and separate family's women. In terms of mental health according to near 166.30 is for the joint family's women and 192.03 is for separate family's women. The difference clearly justifies that joint family's women are under more mental stress in comparison.

(C) Www.ijip.in 
To draw the comparison between the two, I have used ' $t$ ' method is where 4.89 is the out-come. At the level sign force 0.05 and 0.01 levels are significant and as a result the hypothesis of our study is rejected.

Women in separate family can give among time to her own self. She can also spend time with her children. As she is free to take here decisions, her decisions, here mental health is quiet better compared to the women from joint family because the women from separate family can fulfill her needs very often.

\section{Conclusion:}

There is significant difference between joint and separate family's women in mental health.

\section{References:}

1. Dr. Alka M. Mankad, 'Mano Arogya', $1^{\text {st }}$ edition 2006, page No. 75 - 76

2. Haridas M. Nirmal, 'care of mind', $1^{\text {st }}$ edition 2000 Ranguni graphics, Ahmedabad.

3. J. A. Sojitra, Virani, 'Psychological essay', $1^{\text {st }}$ edition, Pashva Publication, Ahmedabad, page No. 115.

4. Mafatlal Patel, 'Abnormal Psychology', $5^{\text {th }}$ edition, university granth Nirman Board, Ahmedabad, page No. 488 - 489.

5. Manisha singh and Girish singh, "Assessment of mental health status of middle aged female school teacher of varanasicity". The Internet journal of health 2006 Vol. 5 No. 1

6. Subhash Basu "Mental Health concerns for Indian Women 2004 India E-mail Dr. Subhashbasu@gmail.com

(C) www.ijip.in 